\section{MODIFICATION OF THE MAZE PROCEDURE FOR ATRIAL FLUTTER AND ATRIAL FIBRILLATION}

\author{
I. Rationale and surgical \\ results
}

The original maze procedure that was described for the treatment of patients with atrial fibrillation was followed by an unacceptable incidence of two problems: (1) the frequent inability to generate an appropriate sinus tachycardia in response to maximal exercise and (2) occasional left atrial dysfunction. In an effort to overcome these problems, we modified the original technique (maze I) twice. The results of these modifications culminated in the maze III procedure, which is associated with a higher incidence of postoperative sinus rhythm, improved long-term sinus node function, fewer pacemaker requirements, less arrhythmia recurrence, and improved long-term atrial transport function. In addition, the maze III procedure is technically less demanding than either the maze I or maze II procedure. Therefore, the maze III procedure is now the technique of choice for the management of medically refractory atrial fibrillation. (J THORAC Cardiovasc Surg 1995;110:473-84)

James L. Cox, MD, John P. Boineau, MD, Richard B. Schuessler, PhD, Robert D. B. Jaquiss, MD, and Demetrios G. Lappas, MD, St. Louis, Mo.
$D^{\prime}$ uring the past several years, the maze procedure has become an important method of treating patients with medically refractory atrial flutter and atrial fibrillation. ${ }^{1-11}$ Follow-up evaluation of the first 32 patients to undergo the maze procedure revealed that two late postoperative problems occurred in some patients: (1) inability to generate an appropriate sinus tachycardia in response to maximal exercise and (2) occasional postoperative left atrial dysfunction. Because of these late postoperative problems, the surgical technique was modified.

Between September 25, 1987, and June 25, 1994, 123 patients underwent the maze procedure for the treatment of atrial flutter or atrial fibrillation, or both. Thirty-two of the first 33 patients underwent the standard maze I procedure (Fig. 1) described previously. ${ }^{4}$ The surgical technique was modified

From the Division of Cardiothoracic Surgery, Department of Surgery, Washington University School of Medicine, Barnes Hospital, St. Louis, Mo.

Supported by National Institutes of Health grant Nos. RO1 HL32257 and RO1 HL33722.

Received for publication Sept. 27, 1994.

Accepted for publication Dec. 14, 1994.

Address for reprints: James L. Cox, MD, Evarts A. Graham Professor of Surgery, Vice-Chairman, Department of Surgery, Chief, Division of Cardiothoracic Surgery, Suite 3108, Queeny Tower, One Barnes Hospital Plaza, St. Louis, MO 63110.

Copyright (C) 1995 by Mosby-Year Book, Inc.

$0022-5223 / 95 \$ 3.00+0 \quad \mathbf{1 2 / 1 / 6 3 0 0 9}$ (maze II procedure) in patients 34 through 48 (Fig. 2) and again (maze III procedure) in patients 49 through 123 (Fig. 3). ${ }^{12}$ Patient 2 underwent the equivalent of the maze III procedure and is included in that group. The demographics of these three groups of patients are listed in Table $\mathbf{I}$.

\section{Rationale for technical modifications}

Inability to generate an appropriate sinus tachycardia after the operation. Detailed electrophysiologic mapping studies in our laboratory have documented the presence of an atrial pacemaker complex both in dogs and in human beings. ${ }^{13,14}$ The atrial pacemaker complex, an area of 2 by $5 \mathrm{~cm}$, is centered about the anatomic sinoatrial (SA) node. Points of earliest activation can occur anywhere within this area, and the site of impulse origin changes, together with changes in rate, in response to differing humoral and neural inputs. For example, during humorally mediated sinus bradycardia (e.g., propanolol-induced), the sinus impulse usually originates from the lower portion of the atrial pacemaker complex near the orifice of the inferior vena cava (IVC) below the anatomic SA node. On the contrary, sinus tachycardia, whether humorally or neurally mediated, can originate from the region of the right atrium immediately anterior to the junction of the superior vena cava (SVC) with the right atrium (Fig. 4).

As originally described, ${ }^{4}$ the maze procedure (maze I) included several incisions around the SA 


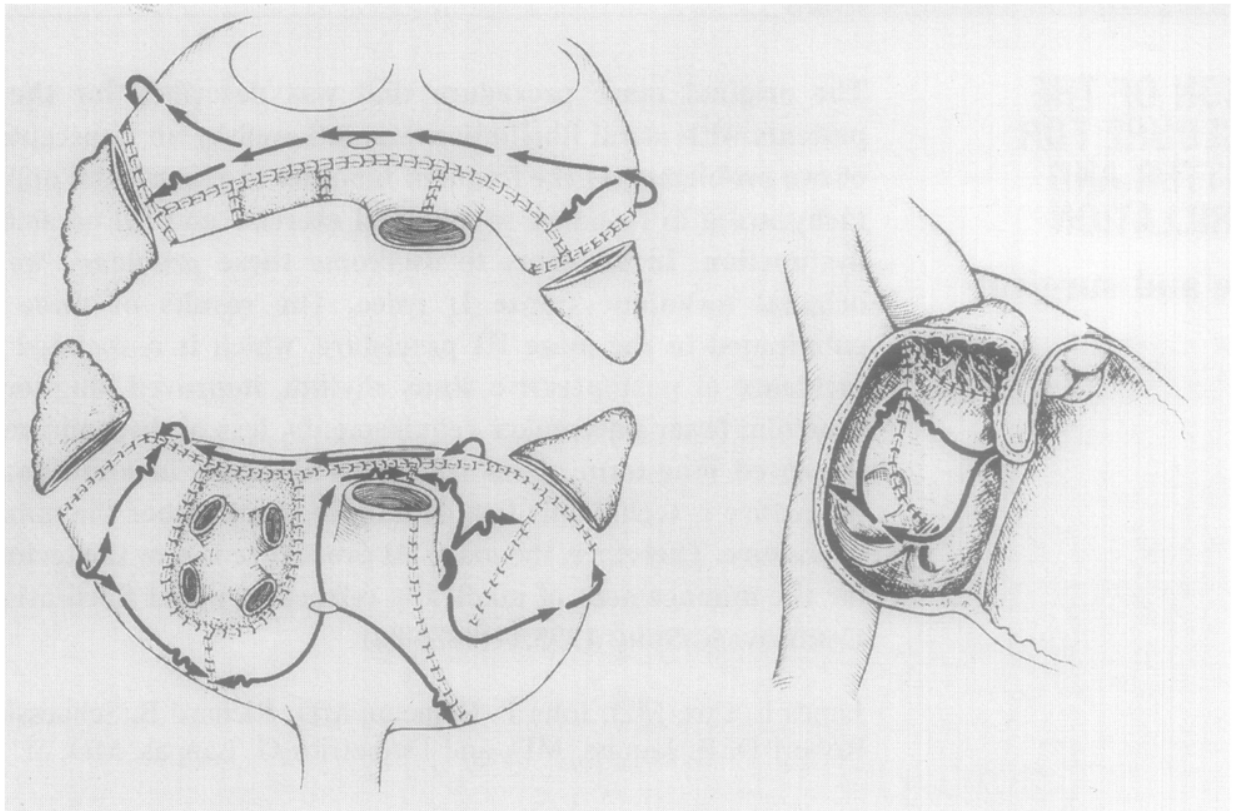

Fig. 1. Two-dimensional representation of the original maze I procedure for atrial fibrillation. In the left panels, the atria are depicted as if viewed from the posterior direction with the back of both atria in the lower panel. The atria are then divided in a sagittal plane and the anterior half of the atria are "flipped" up in the upper panel. The right panel shows the surface of the right atrial septum. Both atrial appendages are excised and the pulmonary veins are isolated. Appropriately placed atrial incisions not only interrupt the conduction routes of the most common reentrant circuits, but they also direct the sinus impulse from the SA node to the atrioventricular node along a specified route. The entire atrial myocardium (except for the atrial appendages and pulmonary veins) is electrically activated, which preserves postoperative atrial transport function. (From Cox JL. Evolving Applications of the Maze Procedure for Atrial Fibrillation [Invited Editorial]. Reprinted with permission from The Society of Thoracic Surgeons. Ann Thorac Surg 1993;55:578-80.)

node, one of which was located directly anterior to the junction of the SVC with the right atrium, that is, through the sinus tachycardia region of the right atrium (Fig. 1). The suspicion that this incision might prevent an appropriate sinus tachycardia after the operation was not raised until well into the clinical series of maze procedures because (1) the inability to generate an appropriate sinus tachycardia after the operation was not recognized initially and (2) the sinus tachycardia region of the right atrium was not identified in human beings until after the maze procedure had been introduced clinically. Once it became apparent that this incision was the most likely reason that an appropriate sinus tachycardia did not develop during maximal exercise in some patients, the incision was eliminated.

The maze I procedure and its first modification (maze II procedure) were evaluated extensively in the research laboratory for several years, the maze II procedure being evaluated exclusively for more than 2 years. ${ }^{3,15-19}$ Once the incisions around the SA node were deleted, it became necessary to add a counterincision on the anterior right atrium to prevent reentry from developing around the base of the right atrium (Fig. 2). The incision that had previously extended from the base of the excised right atrial appendage, across the atrial septum, and then across the dome of the left atrium to the base of the left atrial appendage (Fig. 1) also had to be modified extensively. So that the sinus impulse could travel anteriorly across the left atrium and still not reenter around the SVC orifice, it was necessary to move the left atrial dome incision slightly more posteriorly and to terminate its right end in the medial SVC orifice (Fig. 2).

The combination of moving the left atrial $\mathrm{d}$. incision more posteriorly and adding the ante: right atrial counterincision solved the problem the incisions around the SA node, particularly through the sinus tachycardia region, and it also 


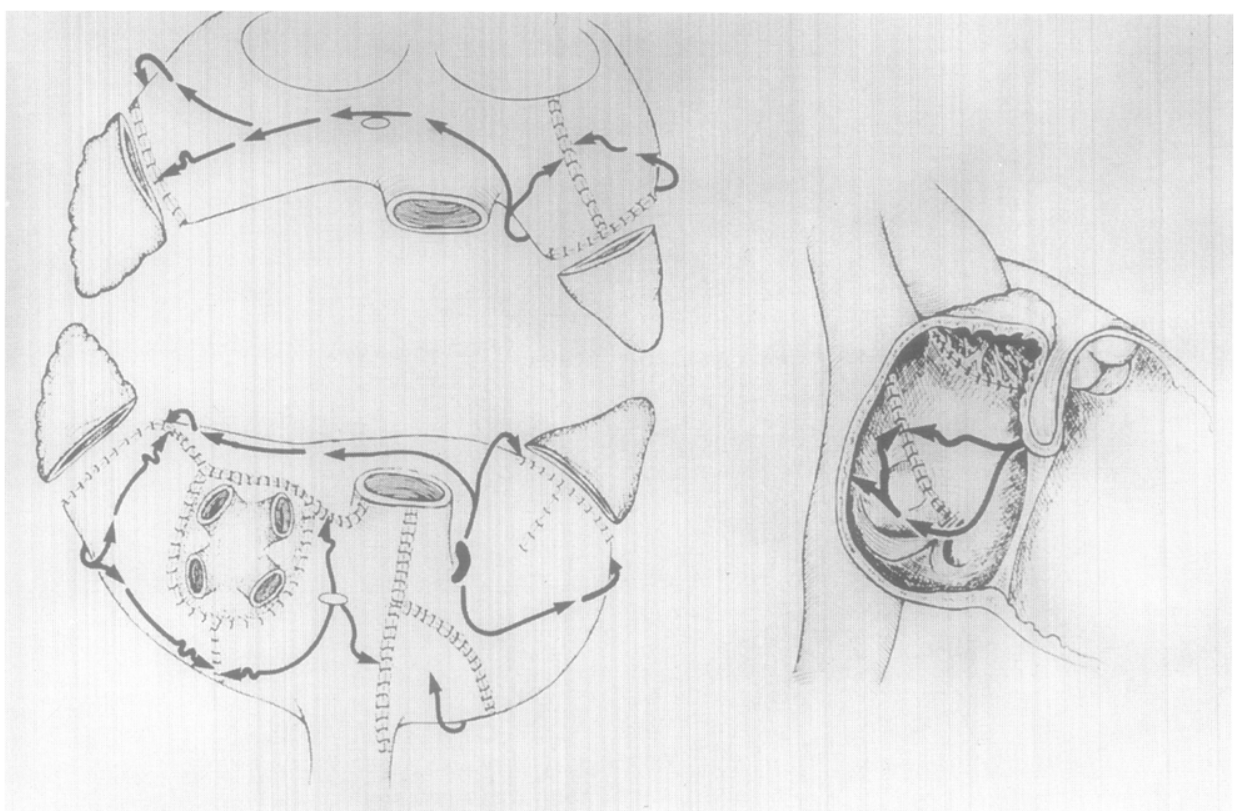

Fig. 2. Maze II procedure: Same views as in Fig. 1. Note that the previous incision through the sinus tachycardia area has been deleted and the transverse atriotomy across the dome of the left atrium has been moved posteriorly to allow better intraatrial conduction. The major problem with this modification of the maze procedure was that is was necessary to completely transsect the SVC to gain exposure of the left atrium. (From Cox JL. Evolving Applications of the Maze Procedure for Atrial Fibrillation [Invited Editorial]. Reprinted with permission from The Society of Thoracic Surgeons. Ann Thorac Surg 1993;55:578-80.)

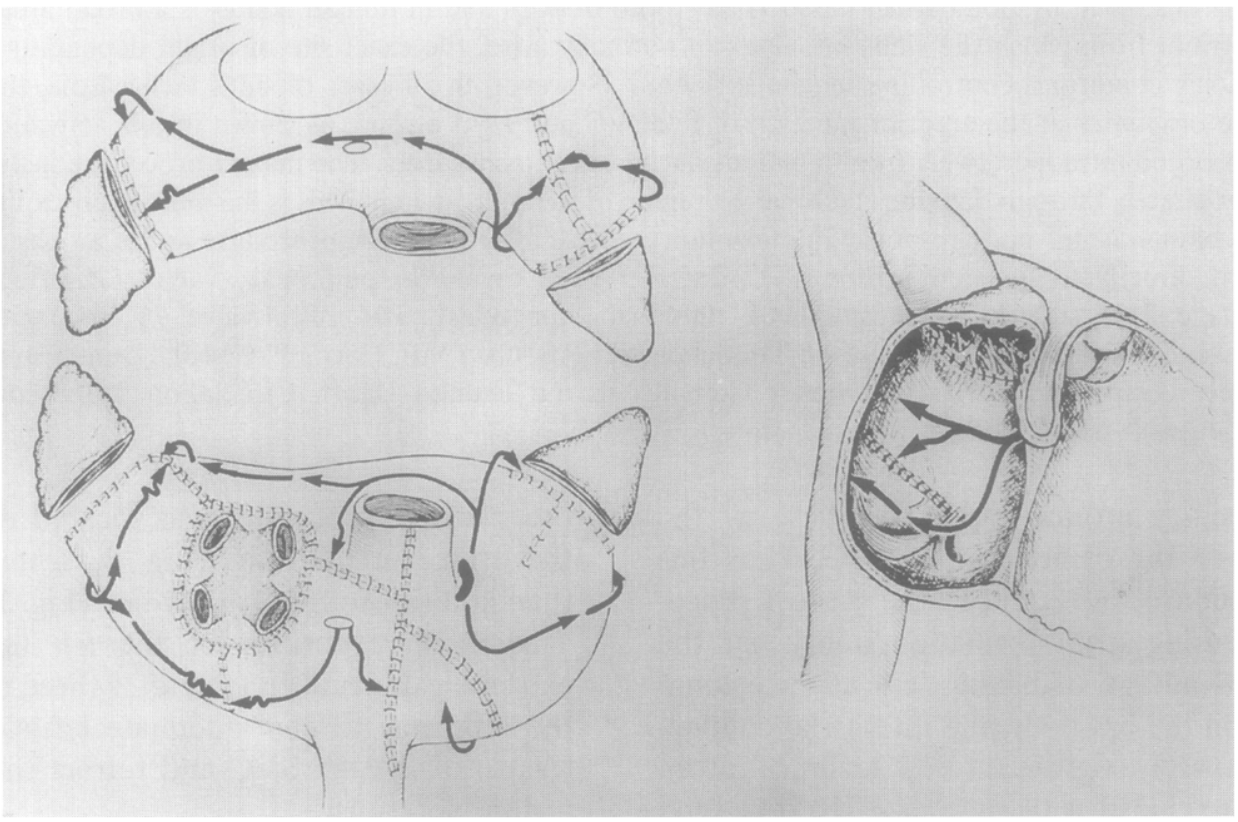

Fig. 3. Maze III procedure: Same view as in Fig. 1. Placement of the septal incision posterior to the orifice of the SVC provides excellent exposure of the left atrium. (From Cox JL. Evolving Applications of the Maze Procedure for Atrial Fibrillation [Invited Editorial]. Reprinted with permission from The Society of Thoracic Surgeons. Ann Thorac Surg 1993;55:578-80.) 


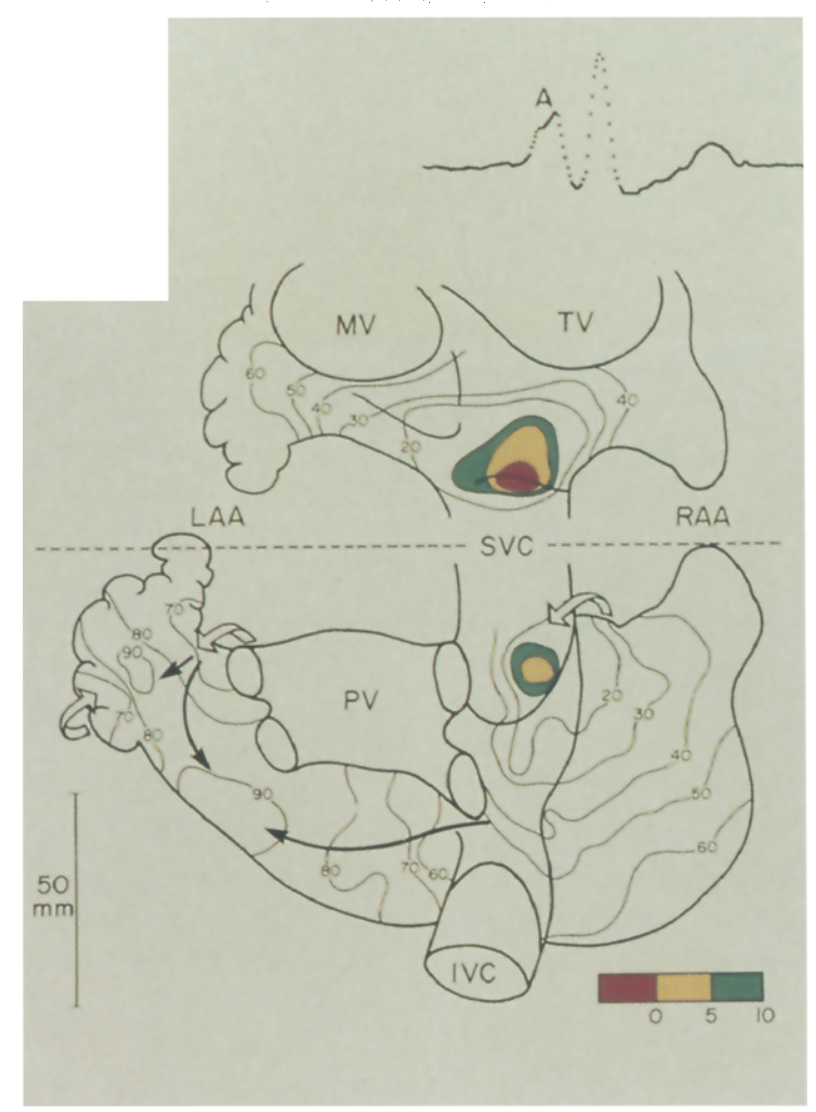

Fig. 4. Site of origin of sinus tachycardia impulses. Same view as left panels of Fig. 1. The atrial pacemaker complex described by Boineau and associates ${ }^{13}$ both in dogs and in human beings is a broad area in the right atrium from which the sinus impulse can normally arise, the exact site of origin depending on the physiologic conditions controlling the sinus rhythm. However, in all cases of sinus tachycardia, the sinus impulse originates at the anterior junction of the SVC and right atrium, as shown in this activation time map recorded intraoperatively from a patient during sinus tachycardia. The maze I procedure includes an incision directly through this sinus tachycardia region of the right atrium. This is the most likely explanation for the blunted sinus node response to maximum exercise after the maze procedure and is an observation that led directly to its modification. $I V C$, Inferior vena cava; $P V$, pulmonary valve; $L A A$, left atrial appendage; $S V C$, superior vena cava; $R A A$, right atrial appendage; $M V$, mitral valve; $T V$, tricuspid valve; $A$, a wave. (From Boineau JP, Canavan TE, Schuessler RB, Cain ME, Corr BP, Cox JL. Demonstration of a Widely Distributed Atrial Pacemaker Complex in the Human Heart. Circulation 1988;77:1221-37. Published with permission.)

prevented reentry around either the base of the right atrium or the orifice of the SVC. Thus this maze II procedure was equal to the maze I procedure in preventing atrial fibrillation, and it had the theoretical advantage of having less adverse longterm effects on the SA node and interatrial conduction. Unfortunately, significant new technical problems were introduced with the maze II procedure. Because the position of the left atrial dome incision determines the position of the atrial septal incision, moving the former more posteriorly also moved the latter more posteriorly. Thus the atrial septotomy in the maze II procedure was located directly below the orifice of the SVC (Fig. 2, right panel) rather than anterior to the SVC orifice (Fig. 1, right panel). This made exposure for the left atrial incisions extremely difficult. In fact, after these modifications, the only way to gain adequate left-sided exposure was to divide the SVC and retract the entire right atrium anteriorly.

It is important to recognize that in both the maze I and the maze II procedures, there are two incisions that terminate in the orifice of the SVC (Figs. 1 and 2). It is virtually impossible to close these two 
incisions without narrowing the distal portion of the SVC. Therefore, it was necessary to patch one of these incisions, our own preference being to use autologous pericardium. Thus, at the completion of the maze II procedure, it was necessary to close the two longitudinal incisions in the distal SVC, patch one of them, and then reapproximate the divided ends of the SVC, all of which occurred in the distal 2 to $3 \mathrm{~cm}$ of the SVC. Because of the fragile nature of the SVC and the extensive surgery required in a small area of the terminal SVC, this was the most technically demanding and time-consuming portion of the maze II procedure. In addition, the maze II procedure did not appear to correct all problems associated with the maze I procedure. As a result, further modifications of the technique were required.

Postoperative left atrial dysfunction. The original animal studies evaluating the effects of the maze I procedure on atrial blood flow confirmed that the multiple atriotomies did not cause any early or late atrial myocardial ischemia. ${ }^{18-20}$ Therefore, the apparent lack of left atrial function in some patients after the operation prompted a search for other causes. Because the right atrium was documented to function normally in all patients both early and late after the operation, it seemed that the most likely explanation for the occasional absence of left atrial function was interatrial conduction delay. The relationship between delayed interatrial conduction and the absence of detectable left atrial function can be explained as follows.

Normally, the sinus impulse originates near the top of the right atrium and propagates rapidly (within approximately $40 \mathrm{msec}$ ) to the top of the left atrium across Bachmann's bundle, a thick band of atrial muscle fibers extending from the region of the SA node to the top of the left atrium. ${ }^{21,22}$ This early arrival of the sinus impulse in the left atrium allows both atria to activate almost simultaneously from top to bottom, which thereby forces blood into their respective ventricles in the most efficient manner. Bachmann's bundle is either divided (Fig. 1) or incorporated (Fig. 2) in the left atrial dome incision in the maze I and maze II procedures, respectively. Therefore, it is not always possible for the sinus impulse to arrive as early as normal in the left atrium. Indeed, after the maze I and maze II procedures, it may occasionally take as long as $\mathbf{1 5 0}$ msec for the sinus impulse to propagate from the right atrium to the left atrium in some patients. If the atrioventricular (AV) interval in such a patient is
Table I. Comparison of patient demographics for the three types of maze procedures

\begin{tabular}{lccc}
\hline \multicolumn{1}{c}{ Demographic } & $\begin{array}{c}\text { Maze I } \\
(n=32)\end{array}$ & $\begin{array}{c}\text { Maze II } \\
(n=15)\end{array}$ & $\begin{array}{c}\text { Maze III } \\
(n=76)\end{array}$ \\
\hline Average age (yr) & $50 \pm 13$ & $52 \pm 12$ & $54 \pm 11$ \\
Male (\%) & 75 & 80 & 72 \\
Paroxysmal AF (\%) & 56 & 40 & 58 \\
Chronic AF (\%) & 44 & 60 & 42 \\
Preop. duration of AF (yr) & $11 \pm 10$ & $6 \pm 5^{*}$ & $9 \pm 8$ \\
Previous operation (\%) & 13 & 0 & 7 \\
Concomitant operation (\%) & 16 & 20 & 34 \\
\hline
\end{tabular}

$A F$, Atrial flutter and/or atrial fibrillation. All comparisons between the maze III procedure and each of the other two procedures are statistically insignificant.

${ }^{*} p<0.05$, maze II compared with maze I procedure.

also $150 \mathrm{msec}$, the sinus impulse will arrive in the left atrium and the left ventricle at virtually the same time. As a result, the left atrium and left ventricle will contract simultaneously and therefore effective left atrial contraction will not occur. However, because right atrial activation will still precede right ventricular contraction by $150 \mathrm{msec}$, right atrial function will appear to be normal. In such a patient, the follow-up studies of atrial transport function will document normal right atrial function with no left atrial function.

In an effort to overcome this problem of prolonged interatrial conduction time, we modified the maze II procedure by moving the entire left atrial dome incision more posteriorly (maze III, Fig. 3). This, in turn, caused the atrial septotomy to be moved more posteriorly as well. This rather minor modification resulted in several dramatic technical and functional improvements in the maze procedure concept. First, with the atrial septotomy now being posterior to the SVC, the exposure of the left side of the heart is superb. Furthermore, in the maze III procedure, only one incision extends into the SVC orifice (Fig. 3); therefore, pericardial patching is no longer necessary. The maze III procedure thus addresses both the chronotropic incompetence of the sinus node and the occasional dysfunction of the left atrium while making the procedure much easier to perform technically.

\section{Results}

Early results $(<3$ months after the operation). Three of 123 patients $(2.4 \%)$ died in the perioperative period, the first after the maze II procedure combined with a Morrow myotomy and myectomy for end-stage hypertrophic obstructive cardiomyopathy. Two deaths followed the maze 
Table II. Perioperative morbidity less than 3 months after the three types of maze procedures

\begin{tabular}{lccc}
\hline \multicolumn{1}{c}{ Postop. complication } & $\begin{array}{c}\text { Maze } I \\
(n=32)\end{array}$ & $\begin{array}{c}\text { Maze II } \\
(n=15)\end{array}$ & $\begin{array}{c}\text { Maze III } \\
(n=76)\end{array}$ \\
\hline Atrial arrhythmias (\%) & 34 & 53 & 45 \\
Fluid retention (\%) & 19 & 7 & 7 \\
Pancreatitis (\%) & 0 & 0 & 4 \\
Hemorrhage (\%) & 9 & 0 & 3 \\
Pneumonia (\%) & 3 & 7 & 1 \\
Low output syndrome (\%) & 3 & 0 & 1 \\
TIA (\%) & 0 & 7 & 1 \\
Myocardial infarction (\%) & 0 & 0 & 1 \\
Stroke (\%) & 3 & 0 & 0 \\
\hline
\end{tabular}

All comparisons among all three procedures are statistically insignificant.

III procedure. The first occurred in a 72-year-old coal miner with black lung disease who died of postoperative respiratory insufficiency, and the second occurred in a 72-year-old man who had an unexpected cardiac arrest as a result of delayed cardiac tamponade. There have been no other early or late deaths.

The most common complications after all three procedures were perioperative atrial arrhythmias and early postoperative fluid retention (Table II). Only one perioperative stroke occurred (maze I), and it completely resolved within several weeks. There were two additional transient ischemic attacks (TIAs) and one perioperative myocardial infarction. Except for postoperative fluid retention, which was recognized after patient 7 and greatly attenuated thereafter by the administration of spironolactone, there were no significant differences in perioperative morbidity among the three procedures.

Late results ( 3 to 81 months after the operation). On June 25, 1994, 111 of the 123 patients had at least 3 months of postoperative follow-up. These late results were tabulated in those 111 patients.

There has been only one late TIA and there have been no late strokes related to the surgical procedures, to the occasional short-term postoperative anticoagulation, or to recurrent atrial arrhythmias. One patient who did not receive anticoagulation had a hemorrhagic stroke 38 months after the operation as a result of long-standing, severe hypertension that was present before the operation.

The TIA occurred in a 48-year-old man who had paroxysmal atrial flutter for 6 years before the operation. He had two thromboembolic episodes before the operation, one TIA and one embolism to the superior mesenteric artery. Postoperatively, he
Table III. Effects of different maze procedures on late $S A$ node function

\begin{tabular}{lrcc}
\hline \multicolumn{1}{c}{ Complication } & Maze I & Maze II & Maze III \\
\hline Inappropriate resting bradycardia & $1 / 32$ & $0 / 14$ & $1 / 65$ \\
Inappropriate resting tachycardia & $4 / 32$ & $0 / 14$ & $8 / 65$ \\
Blunted chronotropic response & $23 / 32$ & $3 / 9$ & $6 / 47^{*}$ \\
\hline
\end{tabular}

The total number of patients evaluated to date appears in the denominator. The numerator represents the number of patients who had a positive finding for the complication listed.

${ }^{*} p<0.001$, maze III compared with maze I.

had a brief episode of atrial flutter at 5 months and another at 19 months. However, the TIA occurred during normal sinus rhythm 12 months after the operation. The TIA involved the face only and resolved completely within 1 hour. The patient is now receiving warfarin and has remained in normal sinus rhythm for the past 18 months.

Postoperative SA node function. The different types of maze procedures had substantially different effects on late function of the SA node (Table III). Using the criteria of a normal SA node before the operation followed by the necessity for a permanent pacemaker after the operation, the surgical procedure itself resulted in injury of the SA node in only two patients, one after the maze I procedure $(3 \%)$ and one after the maze III procedure $(2 \%)$. However, the prevalence of inappropriate resting sinus tachycardia increased with the maze III procedure. This phenomenon occurred between 4 and 12 months after the operation and was characterized by an average resting heart rate of 120 beats $/ \mathrm{min}$. All 15 patients with this problem were successfully treated with low-dose oral $\beta$-adrenergic blockers.

Deletion of the maze I incision through the sinus tachycardia region of the atrial pacemaker complex resulted in an improvement in the ability of the SA node to generate an appropriate sinus tachycardia after the operation (Table III and Fig. 5). The average maximal postoperative heart rate with exercise was $116 \pm 15$ beats/min after the maze I procedure, $132 \pm 14$ beats $/ \mathrm{min}$ after the maze II procedure, and $139 \pm 19$ beats/min after the maze III procedure ( $p<0.05$ comparing maze II to maze I; $p<0.001$ comparing maze III to maze I). This maximum chronotropic response of the SA node to exercise, regardless of the type of maze procedure performed, varies with time (Fig. 6). For example, if the maximum rate response to exercise is plotted against time after operation for each of the three types of maze procedures, regression analysis re- 


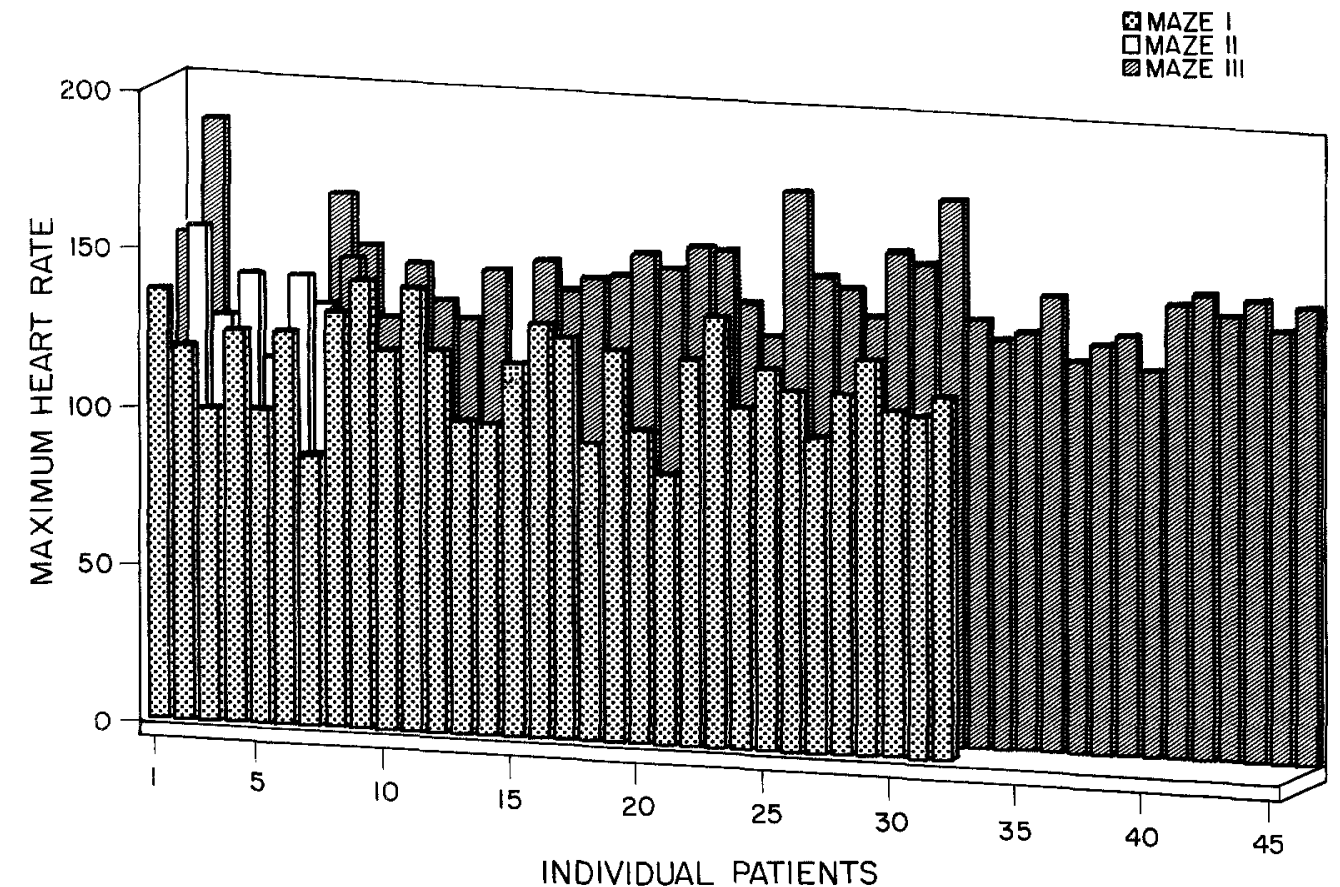

Fig. 5. Maximum heart rate responses during exercise after the maze I, maze II, and maze III procedures. Each bar represents a single patient. The height of the bar denotes the maximal heart rate during exercise. Note that after the maze II and maze III procedures, the sinus node was capable of generating a more rapid rate response to exercise than after the maze I procedure.

veals significance for both the type of operation and the time since operation.

There are numerous reasons why permanent pacemakers are required after the maze procedure, the most common being the presence of preoperative sick sinus syndrome. ${ }^{10}$ Nevertheless, the requirements for permanent pacemakers decreased substantially after the incisions around the SA node were deleted, that is, after the maze II and maze III procedures (Table IV).

Postoperative arrhythmia recurrence. Atrial flutter recurred in five patients, in each case after the maze I procedure (Table V). All five patients were treated successfully with a single antiarrhythmic drug. Seven patients had recurrent atrial fibrillation, three of 32 patients after the maze I procedure $(9 \%)$ and four of $65(6 \%)$ after the maze III procedure. In six of the seven patients the arrhythmia converted to sinus rhythm with medical therapy, and only one patient remains in atrial fibrillation. That patient had a maze I procedure. Thus all patients who had either a maze II or a maze III procedure are now free of atrial flutter and atrial fibrillation (Table VI).

Current cardiac rhythm. After all of the maze procedures combined, $66 \%$ of the patients are in normal sinus rhythm, 33\% are atrially paced, and $1 \%$ remains in atrial fibrillation (Table VII). However, the technical modifications described resulted in an increase in the prevalence of postoperative sinus rhythm from $44 \%$ after the maze I procedure to $75 \%$ after the maze III procedure.

Postoperative atrial function. Immediately after completion of the surgical procedure, both left and right atrial transport function were evaluated in all patients by direct visualization, transesophageal echocardiography, and/or AV pacing versus ventricular pacing at the same paced rates. In addition, most patients underwent either dynamic or threedimensional magnetic resonance imaging and/or transthoracic echocardiography at least once before hospital discharge. It was assumed that any of these tests could give a false negative result, but not a false positive result. Therefore, if any one of these tests indicated the presence of atrial mechanical contraction, atrial transport function was considered to be present in that atrium regardless of the results of the remaining tests. By one or more of these techniques, all patients were documented to have both right and left atrial transport function in the early postoperative period. 


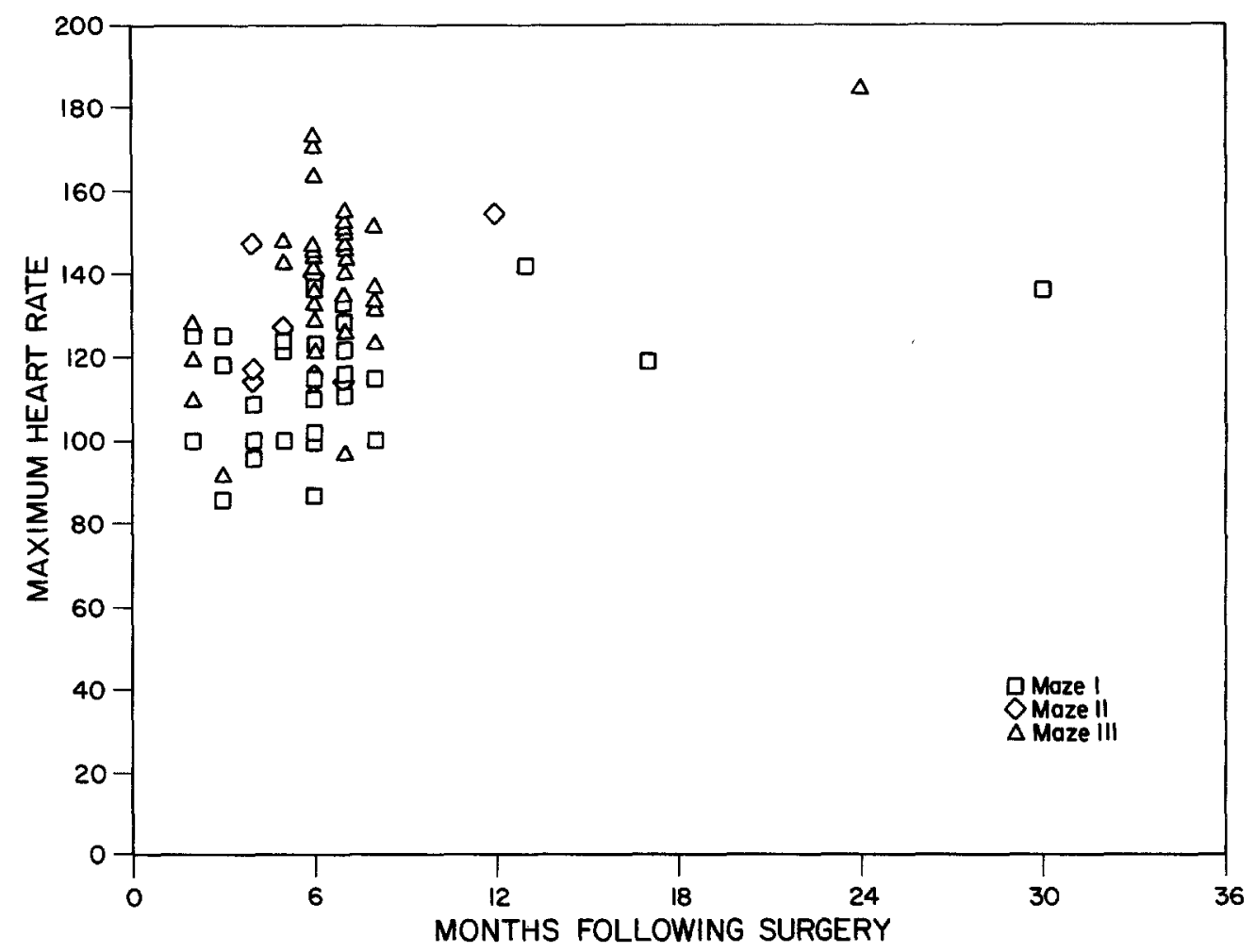

Fig. 6. Regardless of the type of maze procedure performed, the chronotropic response of the sinus node to exercise increases with time. Multiple regression analysis of the data in this graph demonstrate significance for both the type of procedure performed and the length of time after the operation that the patient was evaluated.

Table IV. Permanent pacemaker requirements after the three types of maze procedures

\begin{tabular}{lccl}
\hline Procedure & Pacemakers & $n$ & $\%$ \\
\hline Maze I & 18 & 32 & 56 \\
Maze II & 4 & 14 & 29 \\
Maze III & 16 & 65 & $25^{*}$
\end{tabular}

$n$, Total number of patients followed up for at least 3 months after the operation.

${ }^{*} p<0.005$, maze III compared with maze I.

By June 25, 1994, 90 patients had been reevaluated approximately 6 months after the operation specifically for the presence or absence of right atrial, left atrial, and overall atrial transport function. These evaluations included all of the same tests performed during the operation, except direct visualization, and the same criteria for positive results were used. Right atrial transport function was documented to be present in $98 \%$ of all patients regardless of the type of maze procedure that had been performed (Table VIII). On the contrary, left atrial
Table V. Arrhythmia recurrence after the three types of maze procedures

\begin{tabular}{lcclc}
\hline Procedure & $\begin{array}{c}\text { Atrial } \\
\text { flutter }\end{array}$ & $\begin{array}{c}\text { Atrial } \\
\text { fibrillation }\end{array}$ & Total & $\%$ \\
\hline Maze I & $5 / 32$ & $3 / 32$ & $8 / 32$ & 25 \\
Maze II & $0 / 14$ & $0 / 14$ & $0 / 14$ & 0 \\
Maze III & $0 / 65$ & $4 / 65$ & $4 / 65^{*}$ & $6^{*}$ \\
\hline
\end{tabular}

The total number of patients undergoing a given procedure and followed up for at least 3 months after the operation appears in the denominator. The numerator represents the number of patients who had a recurrence of the arrhythmia listed.

${ }^{*} p<0.02$, maze III compared with maze I.

transport function was present in $72 \%$ of patients after the maze I procedure and in $64 \%$ of patients after the maze II procedure (Table IX). However, further modification of the technique, as described earlier, resulted in left atrial transport function in 94\% of patients after the maze III procedure. Moreover, when compared with ventricular pacing, AV sequential pacing at the same rate resulted in an increase in the thermodilution cardiac output in 52 
Table VI. Control of recurrent arrhythmias following the three types of maze procedures

\begin{tabular}{lccc} 
& & \multicolumn{2}{c}{ Controlled } \\
\cline { 3 - 4 } Procedure & Recurrence & No. & $\%$ \\
\hline Maze I & $8 / 32$ & $31 / 32$ & 97 \\
Maze II & $0 / 14$ & $14 / 14$ & 100 \\
Maze III & $4 / 65^{*}$ & $65 / 65$ & 100 \\
\hline
\end{tabular}

The total number of patients undergoing a given procedure and followed up for at least 3 months after the operation appears in the denominator. The numerator represents the number of patients who had a positive finding for the result listed.

${ }^{*} p<0.02$, maze III compared with maze I.

Table VII. Current cardiac rhythm after the three types of maze procedures

\begin{tabular}{lcccc}
\hline Procedure & $\begin{array}{c}\text { Sinus } \\
\text { rhythm } \\
(\%)\end{array}$ & $\begin{array}{c}\text { Atrial } \\
\text { paced } \\
(\%)\end{array}$ & $\begin{array}{c}\text { Atrial } \\
\text { flutter } \\
(\%)\end{array}$ & $\begin{array}{c}\text { Atrial } \\
\text { fibrillation } \\
(\%)\end{array}$ \\
\hline Maze I & 44 & 53 & 0 & 3 \\
Maze II & 71 & 29 & 0 & 0 \\
Maze III & $75^{*}$ & $25^{*}$ & 0 & 0 \\
Total & 66 & 33 & 0 & 1
\end{tabular}

The total number of patients undergoing a given procedure and followed up for at least 3 months after the operation appears in the denominator. The numerator represents the number of patients who presently have the rhythm listed.

${ }^{*} p<0.02$, maze III compared with maze I.

of 54 patients so evaluated, which confirmed atrial contribution to forward cardiac output in $94 \%$ of all patients, regardless of the type of maze procedure performed.

\section{Discussion}

Because of the documented efficacy of the maze I procedure in ablating atrial flutter and atrial fibrillation, we were reluctant to alter the placement of the atriotomies. However, when it became apparent that several patients had a poor chronotropic response to exercise and others had left atrial dysfunction, experimental studies were initiated to evaluate the possibility of rearranging the atrial incisions to overcome these two problems. One of the risks involved in modifying the maze I procedure was that the modified procedure might prove to be less efficacious in ablating the arrhythmias. In addition, the possibility also existed of replacing one set of postoperative problems with another.

The first modification, the maze II procedure, was extremely difficult to perform technically. Nevertheless, it was eventually introduced clinically and proved to be as safe and effective as the maze I procedure. A further slight modification, however,
Table VIII. The incidence of postoperative right atrial function approximately 6 months after the maze I, maze II, or maze III procedure

\begin{tabular}{lccc}
\hline \multicolumn{1}{c}{ Postop. test } & $\begin{array}{c}\text { Maze I } \\
(n=32)\end{array}$ & $\begin{array}{c}\text { Maze II } \\
(n=11)\end{array}$ & $\begin{array}{c}\text { Maze III } \\
(n=47)\end{array}$ \\
\hline Transesophageal ECHO & N/A & N/A & $5 / 5$ \\
Transthoracic ECHO & $27 / 32$ & $9 / 10$ & $44 / 47$ \\
MRI & $16 / 17$ & $4 / 4$ & $4 / 4$ \\
Total with positive RA & 100 & 100 & 98 \\
$\quad$ function (\%) & & &
\end{tabular}

The total number of patients undergoing a given test appears in the denominator. The numerator represents the number of patients who had right atrial (RA) transport function present as determined by that test. All comparisons among all three procedures are statistically insignificant. $E C H O$, Echocardiography; $M R I$, magnetic resonance imaging; $N / A$, not applicable, that is, the test was not performed. (Note that the total number of patients having positive function may not be the sum of the individual positive tests. The reason is that some patients had two or more tests that were positive and some had only one test that was positive.)

Table IX. The incidence of postoperative left atrial function approximately 6 months after the maze I, maze II, or maze III procedure

\begin{tabular}{lccc}
\hline \multicolumn{1}{c}{ Postop. test } & $\begin{array}{c}\text { Maze I } \\
(n=32)\end{array}$ & $\begin{array}{c}\text { Maze II } \\
(n=11)\end{array}$ & $\begin{array}{c}\text { Maze III } \\
(n=47)\end{array}$ \\
\hline Transesophageal ECHO & N/A & N/A & $5 / 5$ \\
Transthoracic ECHO & $19 / 32$ & $6 / 10$ & $40 / 47$ \\
MRI & $15 / 17$ & $3 / 4$ & $4 / 4$ \\
Total with positive LA & 72 & 64 & $94 \%^{* \dagger}$ \\
$\quad$ function (\%) & & & \\
\hline
\end{tabular}

The total number of patients undergoing a given test appears in the denominator. The numerator represents the number of patients who had left atrial (LA) transport function present as determined by that test. $E C H O$, Echocardiography; $M R I$, magnetic resonance imaging; $N / A$, not applicable, that is, the test was not performed. See text for further discussion. (Note that the total number of patients having positive function may not be the sum of the individual positive tests. The reason is that some patients had two or more tests that were positive and some had only one test that was positive.)

${ }^{*} p<0.02$, maze III compared with maze $\mathbf{I}$.

$t p<0.02$, maze III compared with maze II.

completely changed the degree of technical difficulty and has since become the technique of choice, the maze III procedure. The present analysis of our clinical results indicate that the maze III procedure is likewise as safe and effective as its predecessors. The slightly higher operative mortality rate associated with the maze III procedure in this series reflects the expansion of surgical application to a higher risk group of patients. The perioperative morbidity is essentially the same for all three procedures.

Inappropriate sinus tachycardia is slightly more prevalent several months after the maze III procedure, but this is a minor clinical problem that is easily controlled. More important, after the maze III 
procedure, the pacemaker requirements are less than one half those after the original procedure and the chronotropic response to maximal exercise is entirely normal in more than $87 \%$ of patients. Moreover, inasmuch as the chronotropic response to exercise is time-dependent, this number can be expected to increase on further follow-up. Thus it would appear that deletion of the maze I incision that traversed the sinus tachycardia region of the atrial pacemaker complex alleviated the problem of a blunted sinus node response to postoperative exercise.

Translocating the left atrial dome incision to a more posterior position behind Bachmann's bundle resulted in a higher incidence of detectable left atrial function after the maze III procedure than after either of its predecessors. Indeed, after the maze III procedure, right atrial function is preserved or restored in $98 \%$ of patients and left atrial function is preserved or restored in $94 \%$ of patients. However, even in the patients who have no detectable left atrial function, regardless of the type of procedure, the atria as a whole contribute to the improvement of forward cardiac output. This clinical finding is entirely consistent with the experimental observations made 15 years ago when $\mathrm{we}^{23}$ analyzed the effects of surgical isolation of the left atrium from the rest of the heart. Those studies showed that as long as there is right atrial-to-right ventricular synchrony and preserved right atrial function, the forward cardiac output is normal regardless of whether the left atrium is contracting. In such a situation, the normal right-sided AV synchrony results in a normal right-sided cardiac output, which is delivered, via the pulmonary vascular bed, to the left side of the heart. The left ventricle adapts instantaneously to this normal right-sided output, by increasing its end-diastolic volume, and delivers a normal left-sided output. Neither the synchronicity nor the strength of contraction of the left atrium has any effect on these hemodynamic interactions between the right and left sides of the heart provided the left ventricle is not dysfunctional.

Simply documenting the presence or absence of atrial contraction by one or more of these techniques does not address two important questions regarding how to interpret the functional results of these surgical procedures for the management of atrial fibrillation. The first question is this: "What is the amount of atrial transport function that is preserved or restored after operations for paroxysmal or chronic atrial fibrillation?" Overall atrial trans- port function is easily quantitated by differential atrial versus AV sequential pacing. Although efforts have been made to quantitate individual right atrial or left atrial transport function using Doppler flow studies across the respective AV valves, ${ }^{19}$ no satisfactory method has been developed for quantitating the transport function of one atrium independently from the other atrium. Therefore, although our postoperative Doppler flow studies demonstrate that both right atrial and left atrial transport function are indeed present after the various maze procedures, the magnitude of that atrial contraction in comparison with that of a normal atrium is impossible to quantitate. It is safe to assume, however, that any atrial contraction is better than no atrial contraction, the condition that occurs during atrial fibrillation. Furthermore, our differential pacing studies demonstrate that the synchronous contraction of both atria with the ventricles (AV sequential pacing) results in a substantial increase in forward cardiac output in comparison with that measured in the absence of atrial contraction (ventricular pacing alone).

The second question is this: "How much left atrial function is necessary to alleviate the risk of systemic thromboemoblism?" Although the answer is unknown, some interesting and pertinent observations can be made. It is generally accepted that the major reason that atrial fibrillation leads to mural thrombi in the left atrium is stasis of blood in that chamber. It is important to remember, however, that both atria fibrillate during atrial fibrillation. Therefore, one might expect blood stasis to be just as prominent in the right atrium as it is in the left atrium, yet mural thrombosis in the right atrium with pulmonary embolism is not commonly associated with atrial fibrillation. What is different about the left atrium? The most obvious relevant difference is the compartment-like anatomy of the left atrial appendage with a narrow, definitive introitus and long hollow body that is located peripheral to the main flow stream of blood in the left atrium compared with the broad-based, poorly defined entrance into the shallow right atrial appendage that is immediately adjacent to the main flow stream of blood in the right atrium. Thus excision of the left atrial appendage would intuitively seem to decrease the subsequent threat of left atrial thrombus formation. If, in addition, synchronous contraction of the left atrium with the left ventricle is restored, regardless of how strong or how feeble that contraction, the threat of thromboembolism should be decreased 
even further. Indeed, the pulmonary veins do not contract, yet they are not a source of mural thrombi. Therefore, if the main source of thrombi, the atrial appendage, is removed from the left atrium, and regular, rhythmic blood flow is reestablished through the left atrium by the restoration of a sinus rhythm, it is conceivable that the threat of thromboembolism would be alleviated regardless of whether the left atrium is contracting at all. On the other hand, if the left atrium is contracting, as it has been shown to be in $94 \%$ of our patients, the threat of thromboembolism should be eliminated. This reasoning is consistent with our results in the 28 patients with documented evidence of systemic thromboembolism related to preoperative atrial fibrillation, one of whom had had four separate strokes and a severe myocardial infarction because of embolization of the right coronary artery before the operation. Postoperatively, only one TIA has occurred in any of these patients in nearly 7 years after the maze procedure.

In summary, the original maze I procedure was sometimes followed by an inadequate chronotropic response of the SA node to maximum exercise and by occasional left atrial dysfunction. The technical modifications, culminating in the maze III procedure, have been successful in alleviating those two late postoperative problems without changing the efficacy of the procedure in curing atrial flutter and atrial fibrillation. Indeed, in comparison with the maze I procedure, the maze III procedure is associated with a higher incidence of postoperative sinus rhythm, improved long-term SA node function, fewer pacemaker requirements, less arrhythmia recurrence, and improved long-term atrial transport function. In addition, the maze III procedure is technically less demanding than either the maze I or maze II procedure. For these reasons, the maze III procedure is now the technique of choice for the surgical treatment of patients with atrial fibrillation.

\section{REFERENCES}

1. Cox JL, Schuessler RB, Boineau JP. The surgical treatment of atrial fibrillation. I. Summary of the current concepts of the mechanisms of atrial flutter and atrial fibrillation. J THORAC CARDIovasc Surg 1991;101:402-5.

2. Cox JL, Canavan TE, Schuessler RB, et al. The surgical treatment of atrial fibrillation. II. Intraoperative electrophysiologic mapping and description of the electrophysiologic basis of atrial flutter and atrial fibrillation. J Thorac CARDIOVASC Surg 1991;101:406-26.
3. Cox JL, Schuessler RB, D'Agostino HJ Jr, Stone $\mathrm{CM}$, Chang BC, Cain ME. The surgical treatment of atrial fibrillation. III. Development of a definite surgical procedure. J Thorac Cardiovasc Surg 1991;101:569-83.

4. Cox JL. The surgical treatment of atrial fibrillation. IV. Surgical technique. J Thorac CARdiovasc Surg 1991;101:584-92.

5. Cox JL, Boineau JP, Schuessler RB, et al. Successful surgical treatment of atrial fibrillation. JAMA 1991; 266:1976-80.

6. Cox JL. Surgical treatment of atrial fibrillation [Letter reply]. J THORAC CARDIOVASC SuRg 1992;104:1492-4.

7. Blitz A, McLoughlin D, Gross J, et al. Combined maze procedure and septal myectomy in a septuagenarian. Ann Thorac Surg 1992;54:364-5.

8. Bonchek LI, Burlingame MW, Worley SJ, Vazales BE, Lundy EF. Cox/maze procedure for atrial septal defect with atrial fibrillation: management strategies. Ann Thorac Surg 1993;55:607-10.

9. Hioki M, Ikeshita M, Iedokoro Y, et al. Successful combined operation for mitral stenosis and atrial fibrillation. Ann Thorac Surg 1993;55:776-8.

10. Cox JL, Boineau JP, Scheussler RB, Kater KM, Lappas DM. Five-year experience with the Maze procedure for atrial fibrillation. Ann Thorac Surg 1993;56:814-24.

11. Kosakai Y, Kawaguchi AT, Isobe F, Sasako Y, Kito Y, Kawashima Y. Cox maze procedure for chronic atrial fibrillation associated with mitral valve disease. $\mathbf{J}$ Thorac Cardiovasc Surg 1994;108:1049-55.

12. Cox JL. Evolving applications of the maze procedure for atrial fibrillation [Invited Editorial]. Ann Thorac Surg 1993;55:578-80.

13. Boineau JP, Canavan TE, Schuessler RB, Cain ME, Corr PB, Cox JL. Demonstration of a widely distributed atrial pacemaker complex in the human heart. Circulation 1988;77:1221-37.

14. Boineau JP, Schuessler RB, Canavan TE, Corr PB, Cain ME, Cox JL. The human atrial pacemaker complex. J Electrocardiol 1989;22(Suppl):189-97.

15. Smith PK, Holman WL, Cox JL. Surgical treatment of supraventricular tachyarrhythmias. Surg Clin North Am 1985;65:553-70.

16. D'Agostino HJ Jr, Harada A, Schuessler RB, Boineau JP, Cox JL. Global epicardial mapping of atrial fibrillation in a canine model of chronic mitral regurgitation. Circulation 1987;76(Suppl):IV165.

17. Yamauchi S, Sato S, Schuessler RB, Boineau JP, Matsunaga $Y$, Cox JL. Induced atrial arrhythmias in a canine model of left atrial enlargement. PACE 1990; 13:556.

18. Stone CM, Chang BC, Tweddell JS, et al. Ablation of atrial fibrillation by the maze procedure. Surg Forum 1989;40:213-5.

19. Hand DE, Lappas DG, Hogue CW Jr, Cox JL. 
Perioperative transesophageal Doppler echocardiographic verification of atrial transport function following the maze procedure for atrial fibrillation. Surg Forum 1992;43:267-9.

20. Cox JL, Boineau JP, Schuessler RB, et al. The electrophysiologic basis, surgical development, and clinical results of the maze procedure for atrial flutter and atrial fibrillation. In: Laks H, Wechsler AS, Karp RB, eds. Advances in cardiac surgery. Vol 6. St. Louis: Mosby-Year Book, 1995:1-68.

21. Canavan TE, Schuessler RB, Boineau JP, Corr PB, Cain ME, Cox JL. Computerized global electrophysi- ological mapping of the atrium in patients with WolffParkinson-White syndrome. Ann Thorac Surg 1988; 46:223-31.

22. Canavan TE, Schuessler RB, Cain ME, et al. Computerized global electrophysiological mapping of the atrium in a patient with multiple supraventricular tachyarrhythmias. Ann Thorac Surg 1988;46: 232-5.

23. Williams JM, Ungerleider RM, Lofland GK, Cox JL. Left atrial isolation: new technique for the treatment of supraventricular arrhythmias. J THORAC CARDIOVASC SURG 1980;80:373-80. 